\title{
Cortical nephrocalcinosis in an infant caused by primary hyperoxaluria type 1
}

\author{
Anil Gopalakrishna Rao
}

Received: 16 September 2010 /Revised: 29 September 2010 /Accepted: 30 September 2010 /Published online: 16 October 2010

(C) Springer-Verlag 2010

An 8-month-old boy was referred for an upper gastrointestinal study for vomiting. Scout abdominal radiograph shows bilateral cortical nephrocalcinosis (Fig. 1, arrows). US shows hyperechoic cortical rim with acoustic shadowing confirming cortical nephrocalcinosis (Fig. 2, arrows). Laboratory and genetic testing confirmed primary hyperoxaluria type 1 ( $\mathrm{PH}-1)$.

$\mathrm{PH}-1$ is a rare autosomal-recessive disorder resulting from deficiency of the hepatic peroxisomal enzyme alanineglyoxylate aminotransferase, which causes excessive oxalate formation and calcium oxalate deposition in various organs.

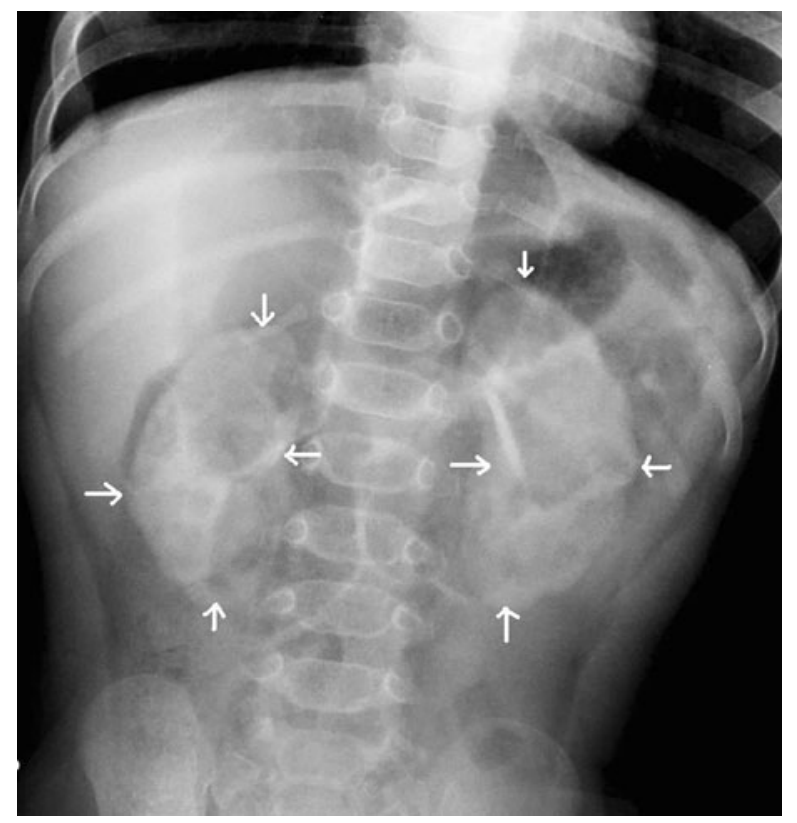

Fig. 1 Abdominal radiograph

A. G. Rao $(\bowtie)$

Radiology and Radiological Science, Medical University of South Carolina,

96 Jonathan Lucas St., MSC 323,

Charleston, SC 29425-3230, USA

e-mail: anilrao.md@gmail.com

e-mail: raoa@musc.edu
Kidneys show cortical or medullary nephrocalcinosis and recurrent urolithiasis causing progressive renal failure [1]. Skeletal manifestations of $\mathrm{PH}-1$ sometimes result from oxalate deposition but more commonly result from chronic renal failure, leading to secondary hyperparathyroidism and renal osteodystrophy [2]. Findings include metaphyseal sclerotic lines and bands, lucent bands, cystic changes, permeative lucencies and vertebral diffuse or endplate osteosclerosis (rugger jersey appearance). Flat pelvic bones, carpal and tarsal bones, and patella might show a radiolucent rim.

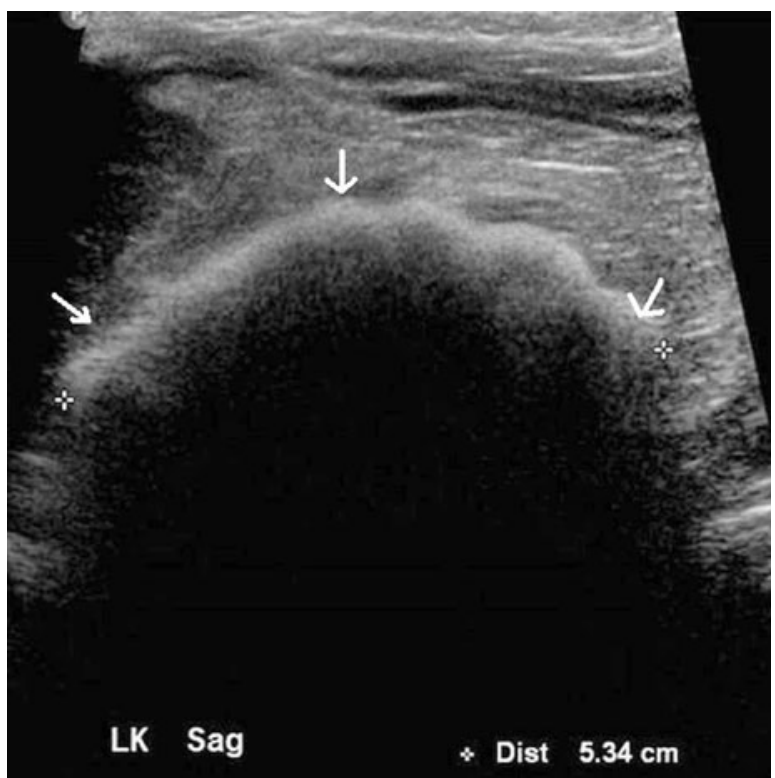

Fig. 2 US of left kidney (longitudinal view)

\section{References}

1. Diallo O, Janssens F, Hall M et al (2004) Type 1 primary hyperoxaluria in pediatric patients: renal sonographic patterns. AJR 183:1767-1770

2. Orazi C, Picca S, Schingo PM et al (2009) Oxalosis in primary hyperoxaluria in infancy. Skeletal Radiol 38:387-391 